\title{
Personal Variables and Perception of Customers on Service Quality of Commercial in Madurai
}

\section{Selvaraj $\mathbf{N}^{*}$}

Saraswathi Narayanan College, Madurai, Tamilnadu, India

\begin{abstract}
Customers have come to gauge the 'technical factors' of services such as core and systematization of the service delivery as the yardstick in differentiating good and bad performance. Customer service is an important adjunct in any undertaking especially in business and service organizations like banks. Day in and day out banks deal with customers, be it the depositors or borrowers or anyone who walks into its portals for transacting any financial business. Now a days, a stiff competition between commercial banks has arisen in providing world class financial services to customers by using information technology, reducing costs, increasing profits and compete with international banks. To explore the relationship between personal variables and the perception of customers on dimensions, the Kruskal Wallis one way ANOVA test was applied. The Kruskal Wallis test was administered to verify that the null hypothesis that there is no significant difference in the perception scores of dimensions among different groups of customers classified according to age, gender, education, occupation, income, type of accounts and customers' duration.
\end{abstract}

Keywords: Perceptions; Banks; Customer and service

\section{Introduction}

Customers have come to gauge the 'technical factors' of services such as core and systematization of the service delivery as the yardstick in differentiating good and bad performance. Researches had also shown that organizations in the service sector are more susceptible to brand loyalty erosions due to falling customer perception of the service.

Customer service is an important adjunct in any undertaking especially in business and service organizations like banks. Day in and day out banks deal with customers, be it the depositors or borrowers or anyone who walks into its portals for transacting any financial business. They now offer a basketful of services to their customers. They are trying to make their customer a "pleased customer" and above all a "satisfied customer" by offering more services than the ingenuity of a customer can demand [1-3].

Now a days, a stiff competition between commercial banks has arisen in providing world class financial services to customers by using information technology, reducing costs, increasing profits and compete with international banks. In the era of technologically backed competition, the awareness level of customers is raising every day. Expectations of customers from banks are mounting to have a wide choice of products and services. The concept of generation to generation banking has also undergone changes [4]. Customer's loyalty is now conditioned by the quality of products of service and their delivery mechanism. All these have necessitated the banks to render warm and excellent customer service [4-6].

\section{Methodology}

The present study is based on both primary and secondary sources. The primary data was collected from the customers of commercial banks by sample survey through structural interview schedule. The secondary data were collected from books, journals, newspapers, periodicals, reports, Internet and the like.

\section{Period of the study}

The study covers a period of ten years from 2005-2006 to 20142015.

\section{Sample Design}

The study entitled customer perception to the services of commercial banks in Madurai city is carried out in the Temple city which is the second largest one in Tamil Nadu. Twenty four public sector banks and fifteen private sector banks function in Madurai district. On the whole twenty branches were selected from public and private sector banks respectively [7].

\section{Field work and collection of data}

Field work for this study was carried out by the researcher himself. The researcher had used the interview schedule for collecting data from bank customers. After collecting the information through the interview schedule the data were verified and edited. The survey was conducted during the period from January 2015 to June 2015.

To explore the relationship between personal variables and the perception of customers on dimensions, the Kruskal Wallis one way ANOVA test was applied.

\section{Relationship between age and perception scores}

The Kruskal Wallis test was administered to verify that the null hypothesis that there is no significant difference in the perception scores of dimensions among different groups of customers classified according to age. The results of the test are presented vide Table 1.

There was a significant difference in the perception scores of the customers on all the dimensions in public sector as well as private

*Corresponding author: Selvaraj N, Assistant Professor of Commerce, Saraswathi Narayanan College, Madurai, Tamilnadu, India, Tel: 9443485379 ; E-mail: profgsk2007@yahoo.co.in

Recieved December 30, 2015; Accepted March 14, 2016; Published March 19 2016

Citation: Selvaraj N (2016) Personal Variables and Perception of Customers on Service Quality of Commercial in Madurai. J Entrepren Organiz Manag 5: 177. doi:10.4172/2169-026X.1000177

Copyright: (c) 2016 Selvaraj N. This is an open-access article distributed under the terms of the Creative Commons Attribution License, which permits unrestricted use, distribution, and reproduction in any medium, provided the original author and source are credited. 


\begin{tabular}{|c|c|c|c|c|c|c|c|}
\hline \multirow[t]{2}{*}{ SI. No } & \multirow[t]{2}{*}{ Various Dimensions } & \multicolumn{3}{|c|}{ Public Sector Banks } & \multicolumn{3}{|c|}{ Private Sector Banks } \\
\hline & & Critical Value & Level of Significance & Result & Critical Value & Level of Significance & Result \\
\hline 1 & Tangibility & 44.362 & 0.000 & $* *$ & 81.309 & 0.000 & ** \\
\hline 2 & Reliability & 13.713 & 0.008 & ** & 170.572 & 0.000 & ** \\
\hline 3 & Responsiveness & 51.029 & 0.000 & ** & 122.867 & 0.000 & ** \\
\hline 4 & Assurance & 54.792 & 0.000 & ** & 134.961 & 0.000 & $* *$ \\
\hline 5 & Accessibility & 60.544 & 0.000 & ** & 38.730 & 0.000 & $* *$ \\
\hline 6 & Empathy & 58.528 & 0.000 & ** & 91.594 & 0.000 & $* *$ \\
\hline 7 & Financial & 31.875 & 0.000 & $* *$ & 36.880 & 0.000 & $* *$ \\
\hline 8 & Technology & 22.798 & 0.000 & $* *$ & 174.644 & 0.000 & ** \\
\hline 9 & Agency & 17.973 & 0.001 & $* *$ & 103.622 & 0.000 & ** \\
\hline 10 & Miscellaneous & 14.808 & 0.005 & $* *$ & 76.131 & 0.000 & $* *$ \\
\hline 11 & Overall & 22.301 & 0.000 & $* *$ & 143.272 & 0.000 & ** \\
\hline
\end{tabular}

Table 1: Relationship between age and perception scores - Kruskal Wallis test.

\begin{tabular}{|c|c|c|c|c|c|c|c|}
\hline \multirow[t]{2}{*}{ SI. No } & \multirow[t]{2}{*}{ Various Dimensions } & \multicolumn{3}{|c|}{ Public Sector Banks } & \multicolumn{3}{|c|}{ Private Sector Banks } \\
\hline & & Critical Value & Level of Significance & Result & Critical Value & Level of Significance & Result \\
\hline 1 & Tangibility & 4.605 & 0.032 & ** & 4.694 & 0.030 & $* *$ \\
\hline 2 & Reliability & 2.408 & 0.121 & NS & 2.039 & 0.153 & NS \\
\hline 3 & Responsiveness & 2.186 & 0.139 & NS & 11.046 & 0.001 & $* *$ \\
\hline 4 & Assurance & 2.033 & 0.154 & NS & 5.626 & 0.018 & $* *$ \\
\hline 5 & Accessibility & 0.051 & 0.822 & NS & 0.197 & 0.657 & NS \\
\hline 6 & Empathy & 0.976 & 0.323 & NS & 5.304 & 0.021 & $* *$ \\
\hline 7 & Financial & 0.224 & 0.636 & NS & 1.049 & 0.306 & NS \\
\hline 8 & Technology & 0.951 & 0.329 & NS & 81.869 & 0.000 & $* *$ \\
\hline 9 & Agency & 8.568 & 0.003 & $* *$ & 19.256 & 0.000 & $* *$ \\
\hline 10 & Miscellaneous & 7.374 & 0.007 & $* *$ & 1.323 & 0.250 & NS \\
\hline 11 & Overall & 0.936 & 0.333 & NS & 17.806 & 0.000 & $* *$ \\
\hline
\end{tabular}

Source: Computed from primary data.

Degree of freedom: $1,{ }^{*}$ Significant at 5 per cent level, NS - Not Significant.

Table 2: Relationship between gender and perception scores - Kruskal Wallis test.

sector banks. It indicated that age factor influenced the dimensions in both public and private sector banks [8].

With regard to the overall score, the value of the level of significance was less than 0.05 ( 5 percent level), and hence the null hypothesis is rejected. It is seen that age factor influenced the perception score of both public and private sector banks.

\section{Relationship between gender and perception scores}

To test whether there is any relationship between the gender and the perception scores of dimensions the following null hypothesis has been framed [9].

There is no significant difference in perception scores among different dimensions based on the gender of the customers. The result of the Kruskal Wallis test is shown vide Table 2.

There was no significant differences in the perception scores of all dimensions expect the tangibility, agency and miscellaneous dimensions in public sector banks. It indicates that the factor gender influenced the tangibility, agency and miscellaneous dimensions. It also showed that the overall perception score, the value of the level of significance was more than the 0.05 ( 5 percent level) and the null hypothesis is accepted. Hence it is concluded that the gender had no influence on the perception score of public sector banks.

As regards private sector banks, there was a significant relationship between the gender and the perception scores of all dimensions except the reliability, accessibility, financial and miscellaneous dimensions. It indicated that gender had no influence on the reliability, accessibility, financial and miscellaneous dimensions. It is also seen that there was significant difference in the overall perception score and hence the null hypothesis is rejected. It is concluded that the gender had influenced the perception score of private sector banks.

\section{Relationship between education and perception scores}

To test whether there is any relationship between the education and the perception scores of dimension the following null hypothesis has been framed.

There is no significant difference in perception scores among different groups of customers based on the education. The results of the Kruskal Wallis test are presented in Table 3.

There was a significant difference in the perception scores of the customers of all dimensions except the agency dimension in public sector banks. It indicated that education had not influenced the agency dimension. It is also seen that there was significant difference in the overall perception score and hence the null hypothesis is rejected. It is concluded that the education had influenced the perception of respondents in public sector banks [10].

In the case of private sector banks, it could be observed that there was a significant difference in the perception score among different customers according to their level of education for all categories. It 


\begin{tabular}{|c|c|c|c|c|c|c|c|}
\hline \multirow[t]{2}{*}{ SI. No } & \multirow[t]{2}{*}{ Various Dimensions } & \multicolumn{3}{|c|}{ Public Sector Banks } & \multicolumn{3}{|c|}{ Private Sector Banks } \\
\hline & & Critical Value & Level of Significance & Result & Critical Value & Level of Significance & Result \\
\hline 1 & Tangibility & 25.050 & 0.000 & $* *$ & 75.218 & 0.000 & ** \\
\hline 2 & Reliability & 14.466 & 0.002 & ** & 84.189 & 0.000 & ** \\
\hline 3 & Responsiveness & 12.515 & 0.006 & ** & 51.312 & 0.000 & ** \\
\hline 4 & Assurance & 51.682 & 0.000 & ** & 42.082 & 0.000 & $* *$ \\
\hline 5 & Accessibility & 15.654 & 0.001 & ** & 14.927 & 0.002 & $* *$ \\
\hline 6 & Empathy & 15.332 & 0.002 & ** & 73.657 & 0.000 & $* *$ \\
\hline 7 & Financial & 36.536 & 0.000 & $* *$ & 36.501 & 0.000 & $* *$ \\
\hline 8 & Technology & 28.849 & 0.000 & $* *$ & 99.119 & 0.000 & ** \\
\hline 9 & Agency & 03.219 & 0.359 & NS & 57.230 & 0.000 & ** \\
\hline 10 & Miscellaneous & 16.301 & 0.001 & $* *$ & 69.386 & 0.000 & $* *$ \\
\hline 11 & Overall & 14.638 & 0.002 & $* *$ & 95.681 & 0.000 & ** \\
\hline
\end{tabular}

Table 3: Relationship between education and perception scores - Kruskal Wallis test.

\begin{tabular}{|c|c|c|c|c|c|c|c|}
\hline \multirow[t]{2}{*}{ SI. No } & \multirow[t]{2}{*}{ Various Dimensions } & \multicolumn{3}{|c|}{ Public Sector Banks } & \multicolumn{3}{|c|}{ Private Sector Banks } \\
\hline & & Critical Value & Level of Significance & Result & Critical Value & Level of Significance & Result \\
\hline 1 & Tangibility & 94.792 & 0.000 & $* *$ & 39.712 & 0.000 & $* *$ \\
\hline 2 & Reliability & 131.751 & 0.000 & $* *$ & 83.550 & 0.000 & ** \\
\hline 3 & Responsiveness & 114.069 & 0.000 & ** & 53.483 & 0.000 & ** \\
\hline 4 & Assurance & 92.337 & 0.000 & $* *$ & 48.514 & 0.000 & $* *$ \\
\hline 5 & Accessibility & 92.036 & 0.000 & $* *$ & 46.615 & 0.000 & $* *$ \\
\hline 6 & Empathy & 102.107 & 0.000 & ** & 92.140 & 0.000 & ** \\
\hline 7 & Financial & 92.654 & 0.000 & $* *$ & 65.737 & 0.000 & ** \\
\hline 8 & Technology & 133.208 & 0.000 & $* *$ & 96.169 & 0.000 & ** \\
\hline 9 & Agency & 95.159 & 0.000 & ** & 61.419 & 0.000 & $* *$ \\
\hline 10 & Miscellaneous & 100.804 & 0.000 & $* *$ & 82.394 & 0.000 & $* *$ \\
\hline 11 & Overall & 124.192 & 0.000 & $* *$ & 90.071 & 0.000 & $* *$ \\
\hline
\end{tabular}

Table 4: Relationship between occupation pattern and perception scores - Kruskal Wallis test.

also shows that for the overall perception score, the value of level of significance was less than the 0.05 ( 5 percent level). Therefore the null hypothesis has been rejected. It is concluded that the education had influenced the perception of customers in private sector banks.

\section{Relationship between occupation pattern and perception scores}

In order to test whether there is any relationship between the occupation pattern and the perception score of dimensions, the Kruskal Wallis test has been applied to the following null hypothesis.

There is no significant difference in perception scores of the dimensions among different groups of customers based on occupation pattern. The results are presented vide Table 4 .

It could be understood that there was a significant relationship between the occupation pattern and the perception scores of all the dimensions in both public and private sector banks. It is also shown that for the overall perception score, the value of level of significance was less than 0.05 ( 5 percent level). Therefore the null hypothesis had been rejected. It is concluded that the occupation pattern had influence on the perception score of public as well as private sector banks.

\section{Relationship between income and perception scores}

In order to test the null hypothesis that there is no significant difference in the perception scores of customers among different groups based on their income, the Kruskal Wallis test has been applied.
The results are given vide Table 5.

It could be seen that there was a significant difference in perception scores among different customers of public sector banks according to income for all categories except tangibility and miscellaneous dimensions [11]. It is also observed that for the overall perception scores, the value of level of significance was less than the 0.05 ( 5 percent level) and therefore the null hypothesis is rejected. It is observed that the factor income had influenced the perception score of public sector banks.

There was a significant difference in the perception scores of all categories of dimensions. The table also shows that for the overall perception scores, the value of level of significance was less than 0.05 (5 percent level) and so the null hypothesis has been rejected. It is determined that the income had influence on the perception scores of private sector banks.

\section{Relationship between type of accounts and perception scores}

In order to test whether there is any relationship between type of accounts and perception scores the following hypothesis has been framed. A Kruskal Wallis test has been used to test the hypothesis.

It was seen that there was no significant difference in the perception scores of dimensions among the different groups based on the type of accounts. The result of the Kruskal Wallis test is shown in Table 6.

There was no significant difference in the perception scores of 


\begin{tabular}{|c|c|c|c|c|c|c|c|}
\hline \multirow[t]{2}{*}{ SI. No } & \multirow[t]{2}{*}{ Various Dimensions } & \multicolumn{3}{|c|}{ Public Sector Banks } & \multicolumn{3}{|c|}{ Private Sector Banks } \\
\hline & & Critical Value & Level of Significance & Result & Critical Value & Level of Significance & Result \\
\hline 1 & Tangibility & 03.316 & 0.506 & NS & 63.872 & 0.000 & ** \\
\hline 2 & Reliability & 30.155 & 0.000 & ** & 40.753 & 0.000 & ** \\
\hline 3 & Responsiveness & 20.871 & 0.000 & $* *$ & 25.605 & 0.000 & ** \\
\hline 4 & Assurance & 25.480 & 0.000 & $* *$ & 27.800 & 0.000 & ** \\
\hline 5 & Accessibility & 40.439 & 0.000 & $* *$ & 22.629 & 0.000 & ** \\
\hline 6 & Empathy & 57.910 & 0.000 & ** & 19.997 & 0.001 & ** \\
\hline 7 & Financial & 30.323 & 0.000 & $* *$ & 22.645 & 0.000 & ** \\
\hline 8 & Technology & 12.024 & 0.017 & $* *$ & 22.755 & 0.000 & ** \\
\hline 9 & Agency & 20.352 & 0.000 & ** & 39.538 & 0.000 & ** \\
\hline 10 & Miscellaneous & 80.821 & 0.066 & NS & 22.502 & 0.000 & $* *$ \\
\hline 11 & Overall & 20.283 & 0.000 & $* *$ & 33.270 & 0.000 & ** \\
\hline
\end{tabular}

Source: Computed from primary data

Degree of freedom: $4,{ }^{*}$ Significant at 5 per cent level, NS - Not Significant.

Table 5: Relationship between income and perception scores - Kruskal Wallis test.

\begin{tabular}{|c|c|c|c|c|c|c|c|}
\hline \multirow[t]{2}{*}{ SI. No } & \multirow[t]{2}{*}{ Various Dimensions } & \multicolumn{3}{|c|}{ Public Sector Banks } & \multicolumn{3}{|c|}{ Private Sector Banks } \\
\hline & & Critical Value & Level of Significance & Result & Critical Value & Level of Significance & Result \\
\hline 1 & Tangibility & 2.964 & 0.397 & NS & 3.424 & 0.331 & NS \\
\hline 2 & Reliability & 5.313 & 0.150 & NS & 3.398 & 0.334 & NS \\
\hline 3 & Responsiveness & 15.993 & 0.001 & ** & 1.595 & 0.661 & NS \\
\hline 4 & Assurance & 3.565 & 0.312 & NS & 1.912 & 0.591 & NS \\
\hline 5 & Accessibility & 4.539 & 0.209 & NS & 1.804 & 0.614 & NS \\
\hline 6 & Empathy & 10.362 & 0.016 & $* *$ & 1.615 & 0.656 & NS \\
\hline 7 & Financial & 8.144 & 0.043 & ** & 1.262 & 0.738 & NS \\
\hline 8 & Technology & 4.383 & 0.223 & NS & 1.577 & 0.665 & NS \\
\hline 9 & Agency & 18.684 & 0.000 & $* *$ & 4.046 & 0.257 & NS \\
\hline 10 & Miscellaneous & 2.092 & 0.553 & NS & 3.521 & 0.318 & NS \\
\hline 11 & Overall & 6.452 & 0.092 & NS & 3.297 & 0.348 & NS \\
\hline
\end{tabular}

Source: Computed from primary data.

Degree of freedom: $3,{ }^{*}$ Significant at 5 per cent level, NS - Not Significant.

Table 6: Relationship between type of accounts and perception scores - Kruskal Wallis test.

all categories of dimensions except in the cases of responsiveness, empathy, financial and agency dimensions in public sector banks. It is also seen that for the overall perception score, the value of level of significance was more than 0.05 ( 5 percent level). Therefore, the null hypothesis has been accepted. It is concluded that the type of accounts had no influence on the perception score of public sector banks.

It could be observed that there is no significant relationship between the type of account and the perception scores of all dimensions in private sector banks. The value of level of significance was more than 0.05 ( 5 percent level). Therefore the null hypothesis is accepted. It is concluded that the type of account had no influence on the perception score of private sector banks.

\section{Relationship between customer duration and perception scores}

In order to test the null hypothesis that there is no significant difference in the perception scores among different groups based on customers' duration, the Kruskal Wallis test has been applied. The results can be found vide Table 7 .

There was a significant difference in the perception scores of the customers of all categories of dimensions in both public and private sector banks in this regard. It is also observed that for the overall perception score, the value of level of significance was less than 0.05 ( 5 percent level). Therefore the null hypothesis is rejected. It is concluded that the customer duration had influenced the perception scores in public as well as private sector banks.

\section{Findings}

\section{Public sector banks}

* There was a significant difference between age and the perception scores of the customers on all the dimensions and the hypothesis indicated that age influences all the dimensions. There was a significant relationship between age and the overall perception of the services.

* There was no significant differences in the perception scores of all dimensions expect the tangibility, agency and miscellaneous dimensions and the hypothesis showed that the factor gender influenced the tangibility, agency and miscellaneous dimensions. There was no significant relationship found between gender and the overall perception of the services.

* There was a significant difference between education and perception scores of the customers of all dimensions except the agency and the hypothesis pointed out that education did not influence the agency dimension. There was a significant difference between education and the overall perception score of the services.

* There was a significant relationship between the occupation pattern and the perception scores of all the dimensions and hypothesis indicated that occupation pattern influenced all the dimensions. There was a significant relationship noticed between occupation pattern and the overall perception score of the services.

* There was a significant difference in perception scores 


\begin{tabular}{|c|c|c|c|c|c|c|c|}
\hline \multirow[t]{2}{*}{ SI. No } & \multirow[t]{2}{*}{ Various Dimensions } & \multicolumn{3}{|c|}{ Public Sector Banks } & \multicolumn{3}{|c|}{ Private Sector Banks } \\
\hline & & Critical Value & Level of Significance & Result & Critical Value & Level of Significance & Result \\
\hline 1 & Tangibility & 30.679 & 0.000 & ** & 58.277 & 0.000 & $* *$ \\
\hline 2 & Reliability & 20.071 & 0.000 & ** & 42.213 & 0.000 & ** \\
\hline 3 & Responsiveness & 21.615 & 0.001 & $* *$ & 51.014 & 0.000 & ** \\
\hline 4 & Assurance & 34.680 & 0.000 & $* *$ & 44.206 & 0.000 & $* *$ \\
\hline 5 & Accessibility & 24.392 & 0.000 & ** & 41.875 & 0.000 & $* *$ \\
\hline 6 & Empathy & 39.434 & 0.000 & $* *$ & 48.351 & 0.000 & $* *$ \\
\hline 7 & Financial & 36.646 & 0.000 & $* *$ & 88.336 & 0.000 & $* *$ \\
\hline 8 & Technology & 51.582 & 0.000 & $* *$ & 25.924 & 0.000 & ** \\
\hline 9 & Agency & 61.916 & 0.000 & $* *$ & 47.771 & 0.000 & $* *$ \\
\hline 10 & Miscellaneous & 78.298 & 0.000 & $* *$ & 63.170 & 0.000 & $* *$ \\
\hline 11 & Overall & 32.066 & 0.000 & $* *$ & 52.812 & 0.000 & ** \\
\hline
\end{tabular}

Table 7: Relationship between customer duration and perception scores - Kruskal Wallis test.

among different customers according to income for all categories of dimensions except tangibility and miscellaneous dimensions and the hypothesis showed that income did not influence the tangibility and miscellaneous dimensions. There was a significant difference between income and the overall perception score of the services.

* There was no significant difference between the type of account and the perception scores of all categories of dimensions except the responsiveness, empathy, financial and agency dimensions and the hypothesis pointed out that the type of account influenced the responsiveness, empathy, financial and agency dimensions. There was no significant relationship between type of account and the overall perception score of the services.

* There was a significant difference between customer duration in the banks and the perception scores of the customers of all categories of dimensions and the hypothesis indicated that the customer duration influenced all the dimensions. There was a significant relationship between customer duration and the overall perception score of the services.

\section{Private sector banks}

* There was a significant difference between age and the perception scores of the customers on all the dimensions and the hypothesis showed that the age influenced all the dimensions. There was a significant relationship between age and the overall perception of the services.

* There was a significant relationship between the gender and the perception scores of all dimensions except the reliability, accessibility, financial and miscellaneous dimensions and the hypothesis pointed out that the gender had did not influence the reliability, accessibility, financial and miscellaneous dimension. There was a significant difference between gender and the overall perception of the services.

* There was significant difference in the perception score among different customers according to their education for all categories and the hypothesis indicated that the education influenced all the dimensions. There was a significant relationship between education and the overall perception score of the services.

* There was a significant relationship between the occupation pattern and the perception scores of all the dimensions and the hypothesis showed that the occupation pattern influenced the all the dimensions. There was a significant relationship between occupation pattern and the overall perception score of the services.
* There was a significant difference between income and the perception scores of all categories of dimensions and the hypothesis pointed out that income influenced all the dimensions. There was a significant difference between income and the overall perception score of the services.

* There was no significant relationship between the type of account and the perception scores of all dimensions and the hypothesis indicated that the type of account did not influence all the dimensions. There was no significant relationship between the type of account and the overall perception score of the services.

* There was a significant difference between the customer duration and the perception scores of the customers of all categories of dimensions and the hypothesis showed that the customer duration influenced all the dimensions. There was a significant relationship between the customer duration and the overall perception score of the services.

\section{Suggestions}

1. The customers of both public as well as private sector banks got the ATM facility within one year. The waiting time for getting ATM facility must be minimized. Efforts should be taken up to provide ATM facility at the time of opening the account itself.

The public sector banks should improve the services which come under the accessibility dimension. In the case of private sector banks, the dimension on miscellaneous factor must be augmented by banks.

\section{References}

1. Abraham $P$ (2011) Emerging role of india's banking sector in promoting inclusive growth: A highlight. Banking sector in global scenario, Sri maruthi publishers, India.

2. Natarajan S, Parameswaran R (2010) Indian Banking. S. Chand \& Company Ltd, New Delhi.

3. www.expressindia.com.

4. RBI Annual Reports 2014-2015.

5. RBI Report on Trend and Progress of Banking in India, 2014-2015.

6. www.banknetindia.com.

7. Ananth A, Ramesh R, Prabaharan B (2011) Service quality gap analysis in private sector banks a customer perspective. Indian Journal of Commerce and Management Studies 2: 245-252.

8. Krishnaswami OR, Ranganatham M (2007) Methodology of research in social science. Himalaya Publishing House, Mumbai. 
Citation: Selvaraj N (2016) Personal Variables and Perception of Customers on Service Quality of Commercial in Madurai. J Entrepren Organiz Manag 5: 177. doi:10.4172/2169-026X.1000177

Page 6 of 6

9. AbdulKalam APJ (2006) Be Leader, Friend and Philosopher. Industrial Herald.

10. Anderson EW, Fornell C, Lehmann DR (1994) Customer satisfaction, market share, and profitability: Findings from Sweden. The Journal of Marketing pp: 53-66.
11. Afsar B, Rehman ZU, Qureshi JA, Shahjehan A (2010) Determinants of customer loyalty in the banking sector: The case of Pakistan. African Journal of Business Management 4: 1040 . 